\title{
Managing urine leakage following laparoscopic radical prostatectomy with active suction of the prevesical space
}

\author{
Milan Hora ${ }^{1,2}$, Petr Stránský1', Jiří Klečka ${ }^{1,2}$, Ivan Trávníček ${ }^{1,2}$, Tomáš Ürge ${ }^{1,2}$, Viktor Eret ${ }^{1,2}$, Jiři Ferda ${ }^{2,3}$, Fredrik Petersson ${ }^{4,5}$, \\ Ondřej Hes ${ }^{2,4}$ \\ 1Department of Urology, Faculty Hospital, Pilsen, Czech Republic \\ ${ }^{2}$ Faculty of Medicine, Charles University, Pilsen, Czech Republic \\ ${ }^{3}$ Department of Radiology, Faculty Hospital, Pilsen, Czech Republic \\ ${ }^{4}$ Department of Pathology, Faculty Hospital, Pilsen, Czech Republic \\ ${ }^{5}$ Department of Pathology, National University Health System, Singapore
}

Videosurgery Miniinv 2013; 8 (1): 49-54 DOI: 10.5114/wiitm.2011.31533

\begin{abstract}
Introduction: Urine leakage following laparoscopic radical prostatectomy $(L R P)$ is a possible complication that may herald chronic urine incontinence. Intraoperative measures aiming to prevent this is not standardised.

Aim: Presentation of experience with active suction of the prevesical space in managing postoperative urine leakage. Material and methods: At the Department of Urology, where laparoscopy of the upper abdomen and open RP were performed, a protocol for extraperitoneal LRP was established in 8/2008. Until 5/2011, 154 LRPs have been performed. Urine leakage from a suction drain appeared in 9 cases (5.8\%). Permanent active suction (with a machine for Büllae thoracic drainage) of the prevesical space with negative pressure of 7-12 $\mathrm{cm}_{\text {of }} \mathrm{H}_{2} \mathrm{O}$ was started immediately.

Results: Urine leakage started after a mean of 0.9 (0-2) days postoperatively and stopped after a mean of 8.1 (15-42) days. Leakage stopped with only suctioning in 7 cases. In one case, open re-anastomosis was performed on the $7^{\text {th }}$ postoperative day (POD). In another case, ineffective active suction was replaced on the 10th POD by needle vented suction without effect and the leakage stopped following gradual shortening of the drain up to the $15^{\text {th }} P O D$.

Conclusions: Active suction of the prevesical space seems to be an effective intervention to stop postoperative urine leakage after laparoscopic radical prostatectomy.
\end{abstract}

Key words: prostate cancer, radical prostatectomy, laparoscopy, complications, urinary leakage.

\section{Introduction}

The main aims of laparoscopic surgery are to minimise abdominal wall injury with the same or better functional and oncological results and as low as possible occurrence of complications [1-3]. In laparoscopic radical prostatectomy (RP) it is not an easy task due to a high risk of many complications. Anastomotic urinary leakage following RP is a well-known complication irrespective of the surgical approach (retropubic, laparoscopic and robotic) and reportedly it may be as high as $13.5 \%$ [4]. However, in most series the frequency is between $2 \%$ and $4 \%$ [5-8]. The effect of the urine leakage on the functional results 
of RP is unknown. Some authors have speculated [9] on whether urine leakage may lead to contracture of the bladder neck, but other investigators do not seem to support this view [10]. Minimizing the risk of postoperative urinary leakage is in our view an important aspect of prostatic surgery. The experience of the surgeon is likely an important factor in minimizing this risk. Due to the relatively low incidence of this postoperative complication and possibly due to reporting bias, postoperative urine leakage is not well covered in the literature.

\section{Aim}

In this paper we present our experience with this complication and suggest that active suctioning of the prevesical space is an effective method in handling this.

\section{Material and methods \\ Operative technique}

In a dorsal supine position with slightly stradled legs, with a $10-15^{\circ}$ head down tilt, a 5-port extraperitoneal approach, antegrade (descending) technique was used. This five-port approach $(2 \times 10 \mathrm{~mm}$, $3 \times 5 \mathrm{~mm}$ ports) requires one surgeon and two assistants. Through a short subumbilical incision, the operative space is created with the index finger and 4 ports are introduced blindly under control of both index fingers or under visual inspection. A video port is applied through an initial incision (Hasson type trocar). Pelvic lymph node dissection (PLND) as a part of the RP was performed in 6 cases; in 5 as a modified

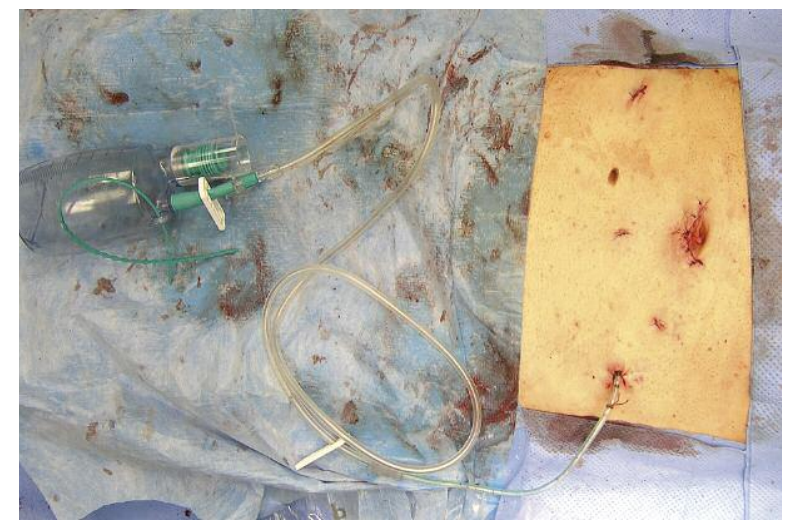

Photo 1. Abdomen following 5-port extracapsular radical prostatectomy. Suction drain $14 \mathrm{~F}$ in the left $5 \mathrm{~mm}$ port procedure. In 1 case an extended PLND was performed [11]. The endopelvic fascia is opened on both sides of the prostate and the Santorini plexus (dorsal vein complex) is ligated with polyglactin suture. The prostate is divided from the bladder neck with a harmonic scalpel or Thunderbeat ${ }^{\circledR}$ Olympus. Complete bladder neck sparing technique was used. The seminal vesicles were dissected. Denonvillier's fascia was opened. The dissection of the prostatic pedicles was performed with a harmonic scalpel or Thunderbeat ${ }^{\circledR}$ (including resection of neurovascular bundles) or in a nerve sparing technique with Hem-o-lok ${ }^{\circledR}$ Weck clips size $L$ and ML. Puboprostatic ligaments, Santorini plexus and urethra were cut with scissors. The prostatic specimen was extracted through a subumbilical incision. We did not use posterior reconstruction of the rhabdosphincter (rebuilding the posterior musculofascial plate) as described by Rocco et al. $[12,13]$ previously; we have started using it since case 150. A urethrovesical anastomosis was performed in three different ways [14] (for details, see below). If a bladder neck preserving technique could not be applied, a bladder neck reconstruction ("tennisracket" reconstruction) was performed at a 6 (in "Van Velthoven" [15] stitch cases) and later at a 12 o'clock position. The water-tightness of the anastomosis was finally controlled by filling with $200 \mathrm{ml}$ sterile water and a $20 \mathrm{~F}$ catheter is introduced and one is withdrawn on the $14^{\text {th }}$ postoperative day (POD). At the end of the surgical procedure a suction drain $14 \mathrm{~F}$ is introduced (Photo 1 ).

\section{Results}

Results are shown in detail in the Table I. Urine leakage started after a mean of 0.9 (0-2) days postoperatively and stopped after a mean of 8.1 (15-42) days. Leakage stopped with only suctioning in 7 cases. In 1 case, open re-anastomosis was performed on the $7^{\text {th }}$ POD. In another case, ineffective active suction was replaced on the $10^{\text {th }}$ POD by needle vented suction without effect and the leakage stopped following gradual shortening of the drain up to the $15^{\text {th }}$ POD. Here, we add some details pertaining to the technique used when creating the urethrovesical anastomosis which is a crucial point for urine leakage. The vesicourethral anastomosis was performed in the first 118 cases with running suture in standard fashion as described by Van Velthoven [15] with poliglecaprone 25 (Monocryl ${ }^{\circledR}$ Ethicon) 3-0. In this group, 


\begin{tabular}{|c|c|c|c|c|c|c|c|}
\hline Follow-up & 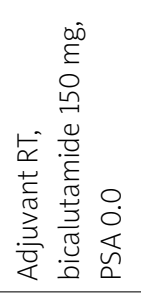 & $\begin{array}{l}\overrightarrow{0} \\
0 \\
0 \\
\overleftarrow{n} \\
0\end{array}$ & 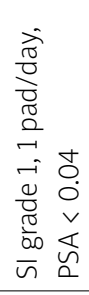 & 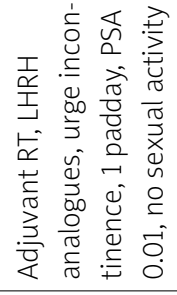 & 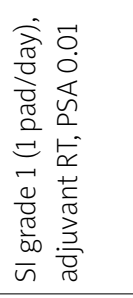 & 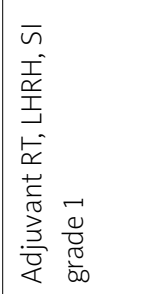 & 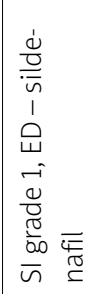 \\
\hline Gleason score & $\begin{array}{l}\underset{f}{+} \\
\stackrel{m}{N} \\
N\end{array}$ & $\begin{array}{l}\widetilde{m} \\
+ \\
\tilde{m} \\
0\end{array}$ & 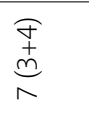 & 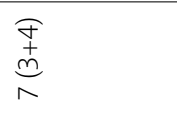 & 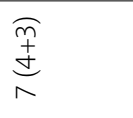 & $\begin{array}{l}\frac{a}{+} \\
\text { 亲 } \\
\sigma\end{array}$ & 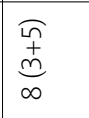 \\
\hline $\mathrm{pN}$ & $\circ$ & 0 & 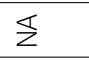 & $\bar{z}$ & o & $\circ$ & $\circ$ \\
\hline $\mathrm{R}$ & - & $\circ$ & $\circ$ & $\rightarrow$ & - & $\circ$ & $\circ$ \\
\hline pT & $\ddot{m}$ & $\breve{\sim}$ & $\breve{\sim}$ & $\breve{\sim}$ & $\vec{m}$ & $\vec{m}$ & $\breve{\sim}$ \\
\hline Preoperative PSA & $\stackrel{m}{m}$ & $\stackrel{9}{\Im}$ & $\stackrel{\infty}{\varphi}$ & $\hat{\infty}$ & $\stackrel{m}{m}$ & $\hat{m}$ & $\underset{\sim}{\stackrel{2}{*}}$ \\
\hline Blood loss & ஓ্ণ & 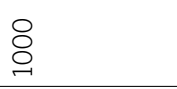 & ষ্ল & 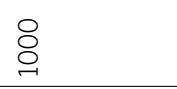 & ৪̀ & 8 & $\stackrel{\text { ৪ }}{m}$ \\
\hline Weight of specimen & $\stackrel{\bullet}{m}$ & $\hat{o}$ & $\vec{\sigma}$ & $\stackrel{\circ}{\bullet}$ & in & $\stackrel{\infty}{+}$ & ఫु \\
\hline Time of surgery & $\stackrel{1}{\circ}$ & $\stackrel{9}{\sim}$ & $\stackrel{\circ}{\circ}$ & ஓ & $\stackrel{n}{\Xi}$ & $\stackrel{\sim}{\sigma}$ & $\stackrel{\stackrel{n}{m}}{\sim}$ \\
\hline Lymphadenectomy & - & - & 0 & 0 & - & $\rightarrow$ & $\rightarrow$ \\
\hline Any antibiotics & $\circ$ & - & $\circ$ & - & $\circ$ & $\rightarrow$ & $\rightarrow$ \\
\hline \multirow{2}{*}{ End of urine leak (postoperative day) } & $\stackrel{\bullet}{\sim}$ & $\stackrel{\curvearrowright}{\sim}$ & $\vec{\sim}$ & 尔 & $\lesssim$ & $\stackrel{\circ}{\sim}$ & $\stackrel{\circ}{\sim}$ \\
\hline & in & $\wedge$ & 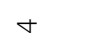 & $\wedge$ & $\Rightarrow$ & $\wedge$ & $\stackrel{n}{\sim}$ \\
\hline \multirow[t]{2}{*}{ Start of urine leak (postoperative day) } & $\circ$ & $\sim$ & $\circ$ & $\rightarrow$ & $\sim$ & - & $\sim$ \\
\hline & 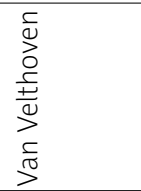 & 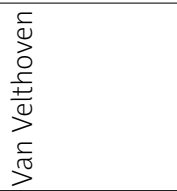 & 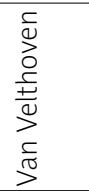 & 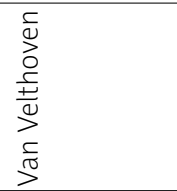 & 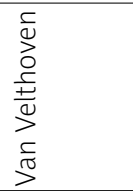 & 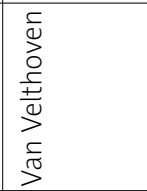 & 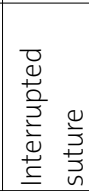 \\
\hline Device & $\stackrel{+}{+}$ & $\stackrel{+}{s}$ & $\stackrel{+}{ \pm}$ & $\stackrel{+}{5}$ & $\begin{array}{l}\overline{\underline{D}} \\
\widetilde{\underline{I}}\end{array}$ & \begin{tabular}{|l}
$\underline{\underline{D}}$ \\
$\underline{\underline{I}}$
\end{tabular} & $\begin{array}{l}\bar{D} \\
\stackrel{\underline{I}}{I}\end{array}$ \\
\hline Note & & 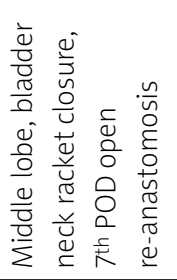 & 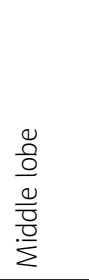 & 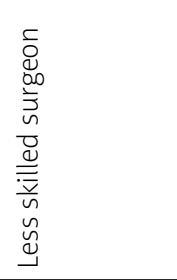 & 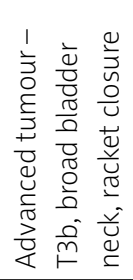 & 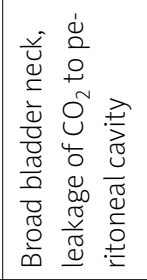 & \\
\hline \multirow{2}{*}{$\begin{array}{r}\text { Leak by test of watertightness at the } \\
\text { finishing of anastomosis with } 200 \mathrm{ml} \\
\text { Date of surgery }\end{array}$} & $\circ$ & $\neg$ & $\circ$ & $\circ$ & $\rightarrow$ & 0 & $\circ$ \\
\hline & 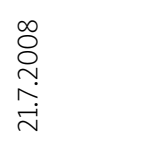 & 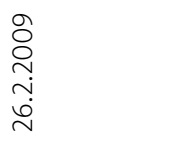 & 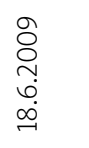 & 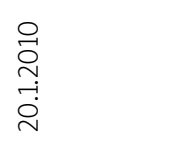 & 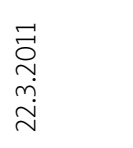 & $\begin{array}{l}\overrightarrow{\tilde{D}} \\
\stackrel{\sim}{ } \\
\sim \\
\sim \\
\sim\end{array}$ & $\begin{array}{l}\overrightarrow{0} \\
\stackrel{0}{0} \\
\stackrel{0}{0} \\
\stackrel{\sim}{0}\end{array}$ \\
\hline Age & $\stackrel{m}{n}$ & $\begin{array}{l}0 \\
\substack{0 \\
0}\end{array}$ & $\stackrel{m}{\vec{b}}$ & $\underset{\mathfrak{N}}{\stackrel{n}{1}}$ & $\overrightarrow{3}$ & $\begin{array}{l}0 \\
\infty \\
i n\end{array}$ & $\begin{array}{l}\hat{\infty} \\
\stackrel{\infty}{\infty}\end{array}$ \\
\hline Order of patient & $r$ & $\stackrel{\sim}{\sim}$ & $\stackrel{\sim}{\sim}$ & 우 & à & $\stackrel{\sim}{\circ}$ & $\stackrel{m}{=}$ \\
\hline Number of patient & $\rightarrow$ & N & $m$ & r & in & 0 & $\wedge$ \\
\hline
\end{tabular}




\begin{tabular}{|c|c|c|c|c|c|c|c|}
\hline Follow-up & 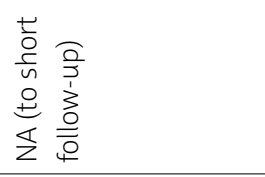 & 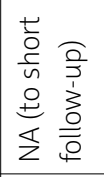 & & & & & \\
\hline Gleason score & $\begin{array}{l}\underset{f}{+} \\
\stackrel{m}{N}\end{array}$ & $\begin{array}{l}\underset{f}{f} \\
\underset{\infty}{ \pm}\end{array}$ & & & & & \\
\hline $\mathrm{pN}$ & $\Sigma$ & $\circ$ & & & & & \\
\hline$R$ & - & o & & & & & \\
\hline pT & $\breve{N}$ & $\frac{0}{m}$ & & & & & \\
\hline Preoperative PSA & $\ddot{n}$ & $\stackrel{\circ}{\circ}$ & & o. & 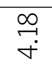 & $\stackrel{\infty}{\infty}$ & $\stackrel{9}{\stackrel{2}{\leftrightarrows}}$ \\
\hline Blood loss & 只 & ঃ & & 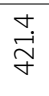 & 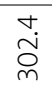 & in & : \\
\hline Weight of specimen & $\hat{n}$ & $\hat{\sigma}$ & & $\begin{array}{l}\stackrel{O}{\circ} \\
\text { in }\end{array}$ & $\begin{array}{l}\infty \\
\stackrel{\infty}{a}\end{array}$ & $\stackrel{\circ}{m}$ & $\infty$ \\
\hline Time of surgery & $\stackrel{\llcorner}{\stackrel{\rho}{a}}$ & $\stackrel{\text { g }}{\rightarrow}$ & & $\begin{array}{l}\hat{\leftrightarrow} \\
\stackrel{\leftrightarrow}{\sigma}\end{array}$ & $\begin{array}{l}\stackrel{\rho}{\infty} \\
\stackrel{m}{m}\end{array}$ & $\stackrel{\leftrightarrow}{\varrho}$ & $\stackrel{q}{\sim}$ \\
\hline Lymphadenectomy & o & $r$ & in & & & & \\
\hline Any antibiotics & o & 0 & 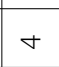 & & & & \\
\hline End of urine leak (postoperative day) & 8 & $\exists$ & & $\begin{array}{l}\infty \\
\dot{m} \\
\dot{m}\end{array}$ & $\hat{\ddot{g}}$ & $\stackrel{\circ}{\stackrel{+}{+}}$ & ०. \\
\hline & $\stackrel{\sim}{\curvearrowleft}$ & $\sim$ & & $\vec{\infty}$ & $\stackrel{\circ}{+}$ & $\stackrel{\text { Oे }}{i}$ & 임 \\
\hline Start of urine leak (postoperative day) & $\circ$ & $\circ$ & & o. & o. & ㅇ. & $\stackrel{\mathrm{i}}{\mathrm{i}}$ \\
\hline Anastomosis & 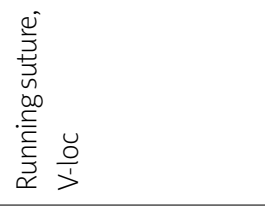 & 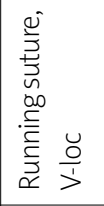 & & & & & \\
\hline Device & & $\mathscr{p}$ & & & & & \\
\hline $\mathrm{CH}_{\mathrm{C}} \mathrm{CH} \mathrm{CH}$ & 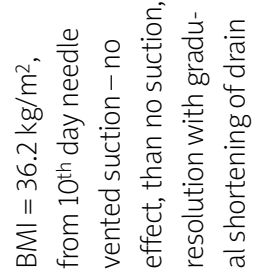 & 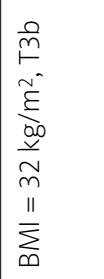 & & & & & \\
\hline $\begin{array}{l}\text { Leak by test of watertightness at the } \\
\text { finishing of anastomosis with } 200 \mathrm{ml}\end{array}$ & ○ & - & m & & & & \\
\hline Date of surgery & 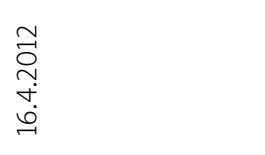 & 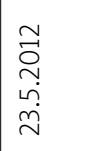 & & & & & \\
\hline Age & $\begin{array}{l}1 \\
\text { Oे }\end{array}$ & $\begin{array}{l}0 \\
\underset{\text { O}}{ }\end{array}$ & & $\begin{array}{l}\stackrel{+}{+} \\
\stackrel{+}{0}\end{array}$ & min & 岕 & $\stackrel{\underset{N}{N}}{ }$ \\
\hline Order of patient & 早 & 守 & \multirow{2}{*}{ 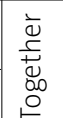 } & \multirow{2}{*}{ 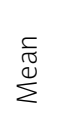 } & \multirow[b]{2}{*}{ in } & \multirow[b]{2}{*}{$\stackrel{\complement}{\sum}$} & \multirow{2}{*}{$\sum_{\substack{x \\
\Sigma}}^{x}$} \\
\hline Number of patient & $\infty$ & $a$ & & & & & \\
\hline
\end{tabular}


leakage was seen in 6 patients (5.1\%). In the 10 subsequent cases, an interrupted suture (6-8) with single polyglactin $\left(\right.$ Vicryl $^{\circledR}$ Ethicon) 3-0 stitches was used [16]; leakage was present in 1 patient (10.0\%). The last 26 cases were sutured by knotless running barbed polyglyconate suture (V-loc ${ }^{\circledR}$ Covidien) 3-0 [17, $18]$. In this group, there were two cases of leakage (7.7\%). In 1 of these patients, the leakage persisted for only 2 days.

\section{Discussion}

The following methods to try to manage postoperative urine leakage from the drain can be applied: (1) Catheter traction (which may damage the bladder neck). (2) Replacing the active suction with passive drainage. This technique may lead to overflow of urine in the pre- and paravesical spaces and may create a nidus for infection). (3) Shortening (pulling back) of the drain (with the risk of loss of drainage of the small pelvis and the formation of a urinoma). (4) Active suction with a Foley urinary catheter (needle vented suction) [19]. In this procedure, a needle is introduced in a supply pipe with negative pressure. The needle prevents the catheter from collapse. We used this technique in the last patient with a previous failure of active suction of the prevesical space, but this method proved to be inefficient. (5) Nephroureteral stent with suction [20]. This technique can be used as a "salvage method" in the event that the previously mentioned (1-4) methods fail. The main disadvantage of this method is that it requires the introduction of a nephrostomy with all the potential complications that are associated with such a procedure. As stated above, all these methods for managing postoperative urinary leakage have their advantages and disadvantages and it is not clear from the literature which is the most preferable. We feel that these methods, for the time being (given the lack of systematic studies), should be used with clinical judgement taking into account the specific constellation of factors that are relevant for a specific patient. A last resort is (6) reoperation. This is probably the most popular method in the event that any of the less invasive methods (1-4) have failed. Castillo et al. [21] accomplished successful laparoscopic repair (reanastomosis) in 4 cases in their series, amounting to $1.0 \%$ of cases in their series of LRP. We opted for this in our case no. 1 on the $7^{\text {th }}$ postoperative day through an open approach. We only found a very small defect.

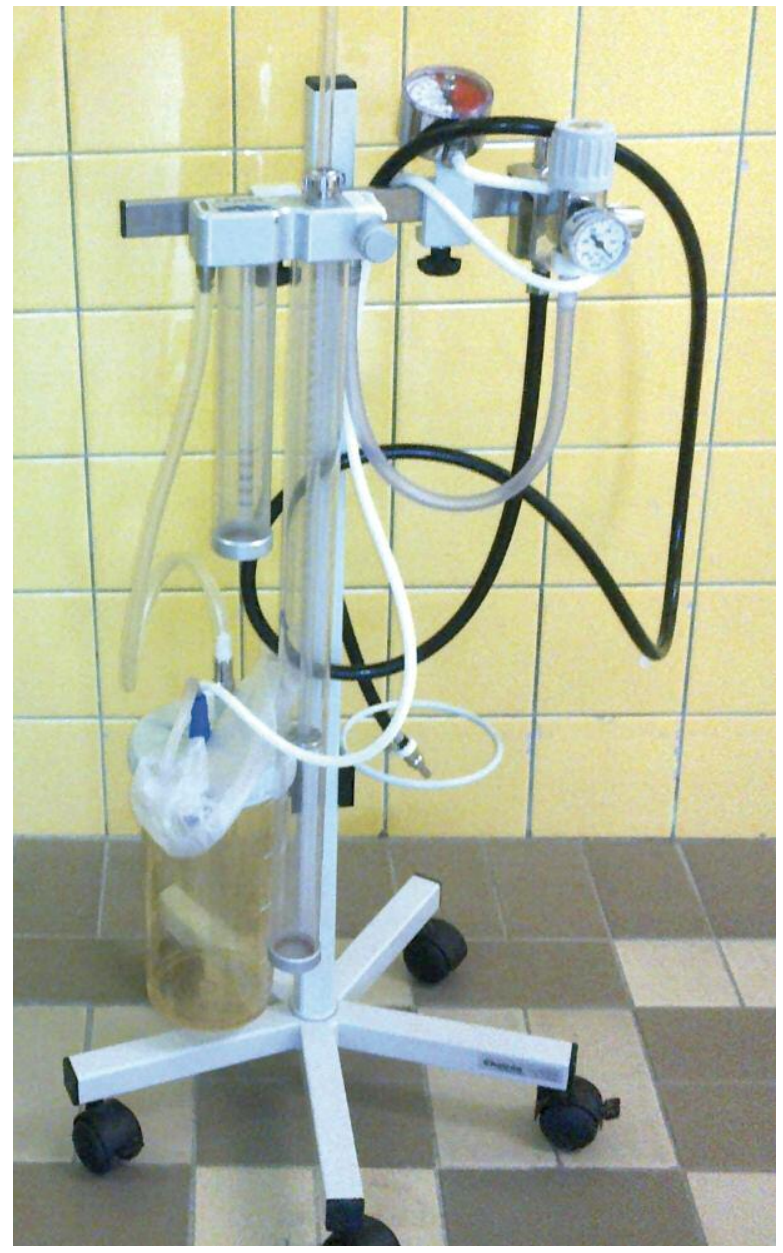

Photo 2. Apparatus for active suction of thorax used for suction of prevesical space. Negative pressure is adjusted to $7-12 \mathrm{~cm}$ of water column (for thorax, $15-20 \mathrm{~cm}$ is used)

Healing of re-anastomosis was smooth. In all the other 8 cases in our cohort, the urine leakage was managed and eventually stopped with non-invasive methods, even if this took up to 15 days. Based on this, in retrospect, we believe that the decision to reoperate patient no. 2 was premature.

\section{Conclusions}

Management of urine leakage following laparoscopic radical prostatectomy is not standardised. In our view, using various methods for active suction of the prevesical space is a practically feasible and frequently successful approach to this problem. The decision to resort to reoperation should not be made prematurely; the leakage may take up to 15 days to 
resolve. The optimal method for active suction of the prevesical space needs further study in relation to various patient-related factors.

\section{Acknowledgments}

The work was supported by the Czech government research project MSM 0021620819 and by the project of the Ministry of Health, Czech Republic for conceptual development of research organization 00669806 - Faculty Hospital in Pilsen, Czech Republic.

\section{References}

1. Rembiasz K, Bobrzyński A, Budzyński A, et al. Analysis of complications of laparoscopic management of abdominal diseases related to extended indications. Videosurgery Miniinv 2010; 5 : 53-9.

2. Skrovina M, Soumarova R, Kycina R, et al. Anastomotic leakage after laparoscopic total mesorectal excision for low rectal cancer. Videosurgery Miniinv 2011; 6: 5-11.

3. Chłosta P, Drewa T, Obarzanowski M, et al. Do we need a cosmetic effect for radical nephrectomy? Laparoendoscopic singlesite surgery would help to answer this question. Videosurgery Miniinv 2011; 6: 1-4.

4. Liatsikos E, Rabenalt R, Burchardt M, et al. Prevention and management of perioperative complications in laparoscopic and endoscopic radical prostatectomy. World J Urol 2008; 26: 571-80.

5. Abbou CC, Salomon L, Hoznek A, et al. Laparoscopic radical prostatectomy: preliminary results. Urology 2000; 55: 630-4.

6. Doležel J, Tvarůžek J, Staník M, et al. Our early experience with robotic-assisted laparoscopic radical prostatectomy - first 153 cases. Ces Urol 2009; 13: 168-77.

7. Ahmed F, Rhee J, Sutherland D, et al. Surgical complications after robot-assisted laparoscopic radical prostatectomy: the initial 1000 cases stratified by the Clavien Classification System. J Endourol 2012; 26: 135-9.

8. Yuh BE, Ruel NH, Mejia R, et al. Robotic extended pelvic lymphadenectomy for intermediate- and high-risk prostate cancer. Eur Urol 2012; 61: 1004-10.

9. Webb DR, Sethi K, Gee K. An analysis of the causes of bladder neck contracture after open and robot-assisted laparoscopic radical prostatectomy. BJU Int 2009; 103: 957-63.

10. Hanson GR, Odom E, Borden LS Jr, et al. Post-operative drain output as a predictor of bladder neck contracture following radical prostatectomy. Int Urol Nephrol 2008; 40: 351-4.

11. Liatsikos E, Kyriazis I, Kallidonis P, et al. Comments on the extraperitoneal approach for standard laparoscopic radical prostatectomy: what is gained and what is lost. Prostate Cancer 2011; 2011: 150978. Epub 2011 Sep 22. doi: 10.1155/2011/150978.

12. Rocco B, Gregori A, Stener S, et al. Posterior reconstruction of the rhabdosphincter allows a rapid recover of continence after transperitoneal videolaparoscopic radical prostatectomy. Eur Urol 2007; 51: 996-1003.
13. Sano T, Nakashima M, Haitani T, et al. Posterior musculofascial plate reconstruction promotes early restoration of continence and prevents severe incontinence in patients undergoing laparoscopic radical prostatectomy. Int J Urol 2012; 19: 475-9.

14. Teber D, Erdogru T, Cresswell J, et al. Analysis of three different vesicourethral techniques in laparoscopic radical prostatectomy. World J Urol 2008; 26: 617-22.

15. Van Velthoven RF, Ahlering TE, Peltier A, et al. Technique for laparoscopic running urethrovesical anastomosis: the single knot method. Urology 2003; 61: 699-702.

16. Stolzenburg JU, Do M, Pfeiffer H, et al. The endoscopic extraperitoneal radical prostatectomy (EERPE): technique and initial experience. World J Urol 2002; 20: 48-55.

17. Chapman S, Tur R, Cross W. Vesicourethral anastomosis using $\mathrm{V}$-Loc ${ }^{\text {TM }}$ barbed suture during robot-assisted radical prostatectomy. CEJU 2011; 64: 236.

18. Zorn KC, Trinh QD, Jeldres C, et al. Prospective randomized trial of barbed polyglyconate suture to facilitate vesico-urethral anastomosis during robot-assisted radical prostatectomy: time reduction and cost benefit. BJU Int 2012; 109: 1526-32.

19. Moinzadeh A, Abouassly R, Gill IS, Libertino JA. Continuous needle vented Foley catheter suction for urinary leak after radical prostatectomy. J Urol 2004; 171: 2366-7.

20. Shak G, Vogel F, Moinzadeh A. Nephroureteral stent on suction for urethrovesical anastomotic leak after robot-assisted laparoscopic prostatectomy. Urology 2009; 73: 1375-6.

21. Castillo OA, Alston C, Sanchez-Salas R. Persistent vesicourethral anastomotic leak after laparoscopic radical prostatectomy: laparoscopic solution. Urology 2009; 73: 124-6.

Received: 3.07.2012, revised: 26.07.2012, accepted: 28.08.2012. 